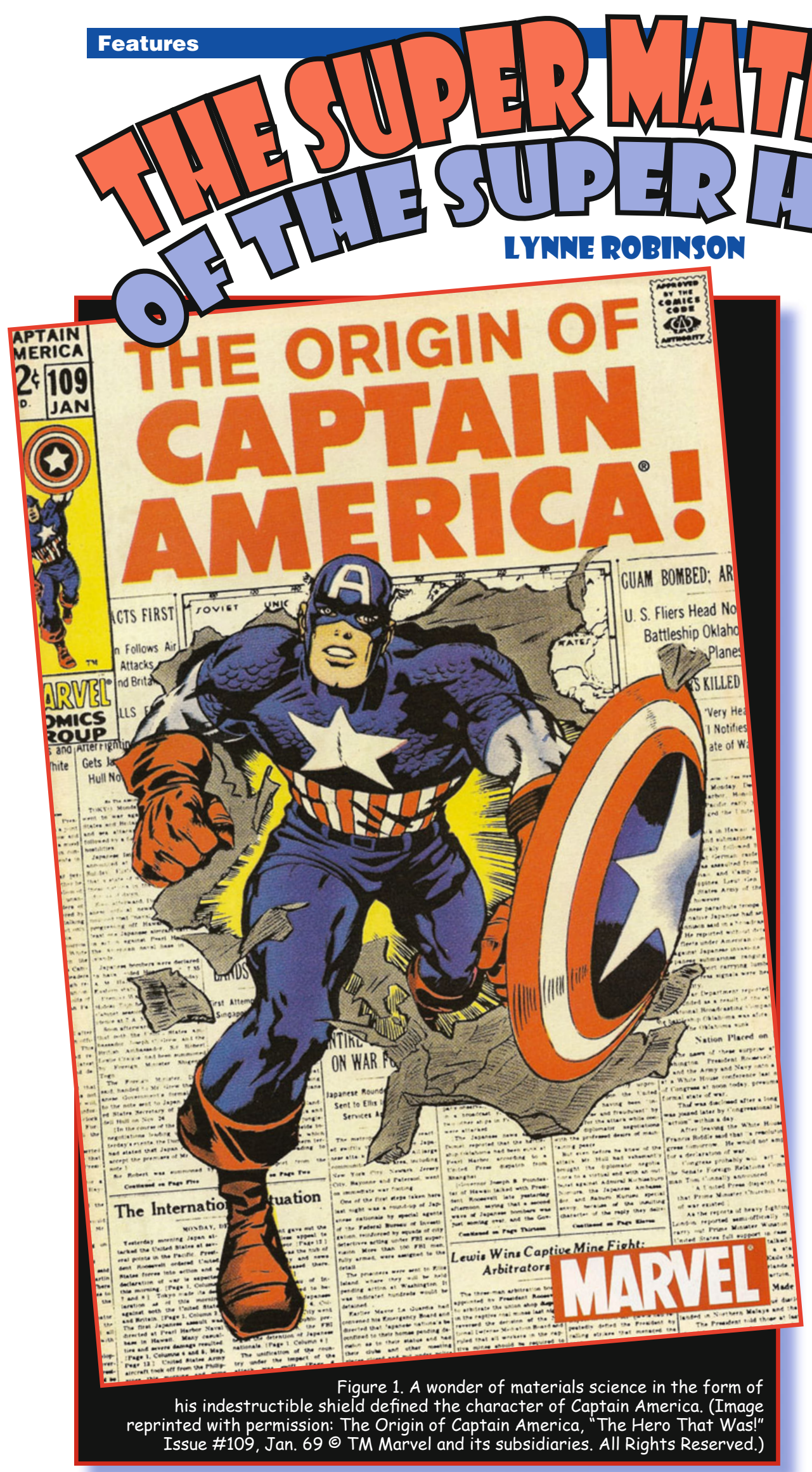

Granted, in some circles, superhero comics are not considered high culture. For the millions who will be flocking to local movie theaters this summer to catch the big-screen adventures of the Avengers, Spider-man or Batman, they are simply entertaining stories told with bigger-than-life characters and special effects. On a more resonant level, however, these fantastic sagas have woven together a mythology for the modern age, tracing society's perception of and relationship with scientific advancement. Both brilliant and mighty, the heroes and villains of these tales echo ancient themes and struggles, told within the context of extreme scientific possibility.

It's also frequently the materials science involved that defines these characters and the parameters of their power. And, while some scientific descriptions might seem to push the boundaries of plausibility, Suveen N. Mathaudhu, program manager, Synthesis and Processing of Materials, U.S. Army Research Office, notes that advanced processing and characterization technologies, coupled with computational materials design tools and strategies, have closed the gap between comic fiction and science reality. "There really is very little reason that we should not be able to microstructurally engineer whatever materials we want for the future," he said.

As a case in point, Mathaudhu recently issued a request for white papers based on the theme of "the making of Captain America's shield." Captain America burst upon a frightened and war-torn world from the pages of his self-titled Marvel comic book in 1941, ready and eager to vanquish the Axis powers with superior strength and skills gained from an experimental "super soldier serum." 
His weapon of choice was a shield capable of absorbing, storing, and redirecting all the kinetic energy and vibrations hurled at it (Figure 1). The more energy it absorbed within the bonds between its molecules, the more powerful the material became. The fictional element making these unique properties possible was "vibranium," obtained from a meteorite that fell to Earth in Africa. When bonded with steel and an unknown catalyst, the vibranium formed an indestructible alloy that could only be reshaped by molecular rearrangement.

To Mathaudhu, the real hero of the Captain America legend is Dr. Myron MacLain, an American metallurgist. At the urging of President Roosevelt, MacLain was attempting to develop an indestructible tank armor to give the Allied forces an edge on the battlefield.

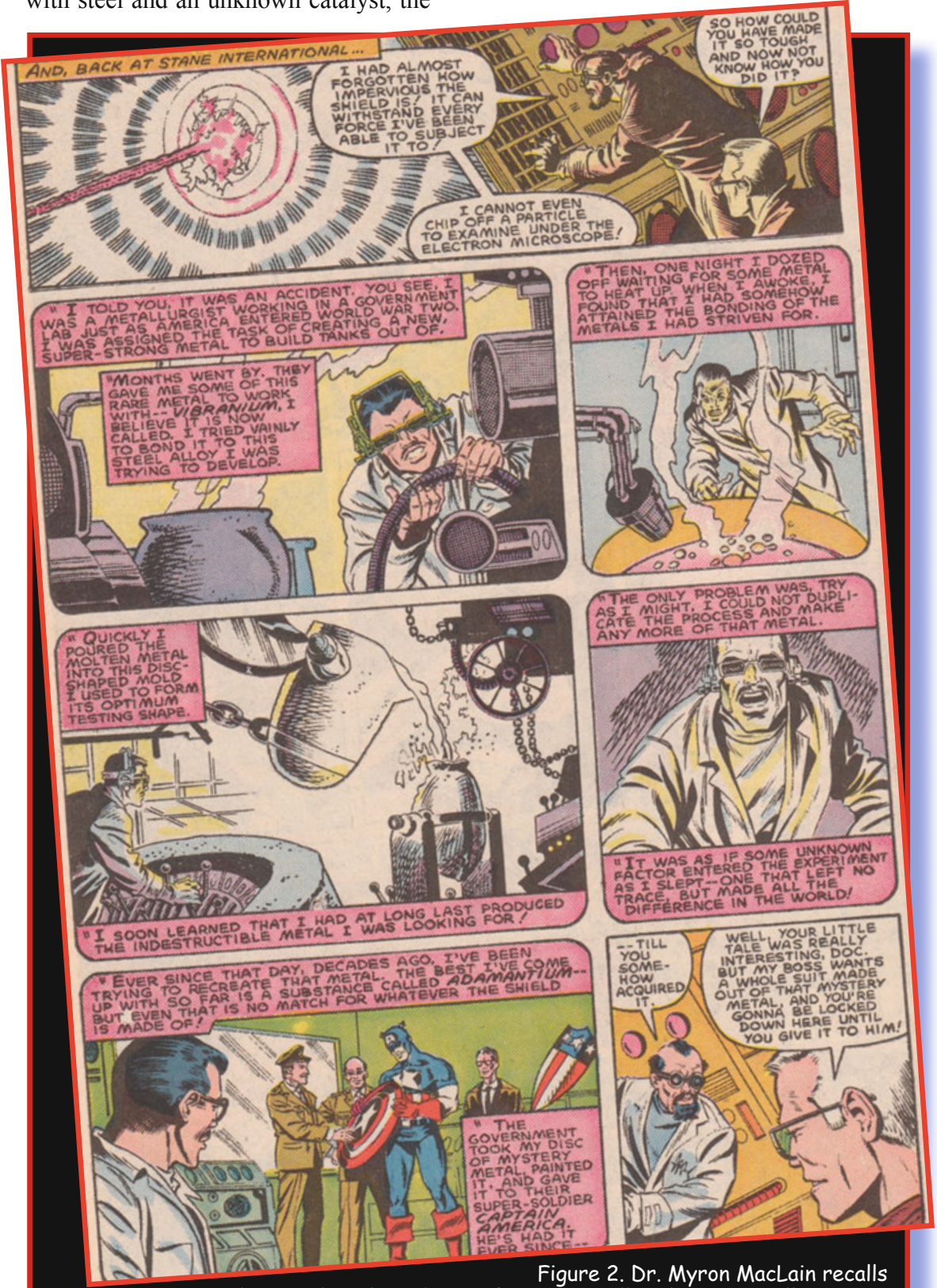

his accidental synthesis of vibranium alloy that eventually became Captain America's indestructible shield. As noted by Suveen N. Mathaudhu, U.S. Army Research Office, MacLain's quest to recreate the mysterious alloy could be facilitated today by an array of advanced characterization, simulation and computational design tools, enabling the ability to engineer the microstructure of materials to achieve almost equally amazing properties. (Image reprinted with permission: Captain America V1 V303 Mar. 85 ๑ TM Marvel and its subsidiaries. All Rights Reserved.)

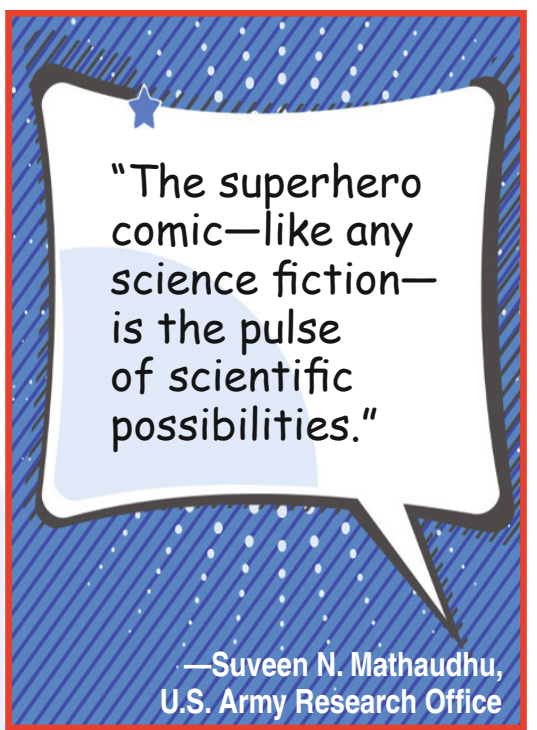

While experimenting with vibranium, he nodded off and the alloy mysteriously formed while he slept.

MacLain was never able to recreate the material in his lab again (Figure 2), although Mathaudhu believes he would have a fighting chance with technologies from the "real world" that have eclipsed imagination (Figure 3). "We have control over the atomic world that we didn't have 20 years ago," he said. "Through high-end microscopy tools, we can visualize and manipulate the very microstructure of a material to achieve ultrahigh strength and other truly amazing characteristics. The next frontier is the ability to accurately predict how we can create materials with specific properties - a true materials by design capability."

Encouraging breakthroughs to that next frontier was the intent of Mathaudhu's Captain America challenge. "The superhero comic - like any science fiction - is the pulse of scientific possibilities," he said. "People relate to these stories and can tie them uniquely to their own ideas. I often use examples like this in presentations as a means of inspiring the next generation of engineers - to get them to think differently about what could be possible and then push to that next level."

Like the fictional MacLain, Mathaudhu's work focuses on discovering materials technologies that will eventually protect soldiers in the field. "Throughout history, the military has looked for ways to make better shields - stronger, 


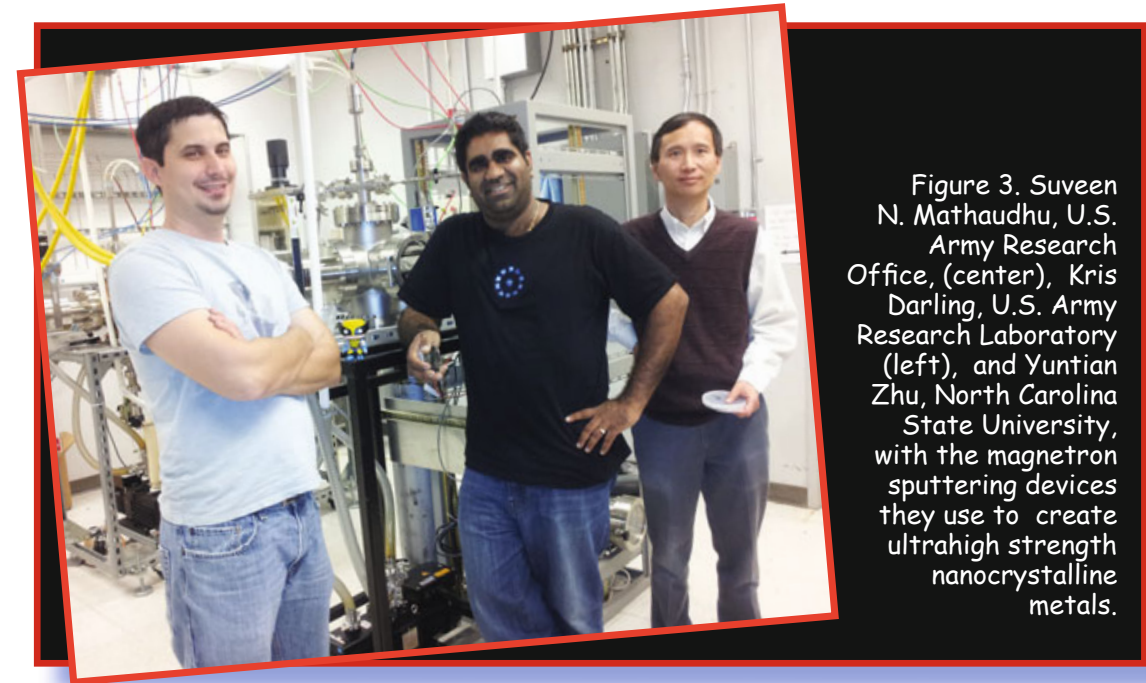

lighter materials that absorb and reflect energy in defense of the soldier. So, it's not surprising that the strength of many superheroes comes from their armor," he said. "The basic science and research that I'm involved with now is relevant to soldiers 20 years from now. But it still really comes down to making a better shield — or at least a futuristic version of one."

\section{THE MATERRTALS OF MYVHOLOGY}

Shields, weapons, and superpowers enabled - and in many plot lines, challenged - by science are actually a more recent concept explored in the comic book world. The earliest superheroes tended to draw their powers from myth and magic - if they had any powers at all. Their arch foes were corrupt landlords and businessmen and their adventures reflected the concerns and experiences of a Great Depression society. "Superman is actually the comic version of the American immigrant story," said Wayne Wise, a comic expert with the ToonSeum, a museum located in Pittsburgh, Pennsylvania, devoted to the art of cartooning. "Like many people at the time, his homeland had been destroyed and he came to America to find opportunity - to be the best that he could be. He fought what his readers were fighting and embodied the best American ideals.'

Superman, when he debuted in Action Comics \#1 in 1938, actually resembled Hercules more than the high-tech extraterrestrial that he is known as today. He could "leap tall buildings in a single bound," but did not fly, and while he was very strong, many of his other traits had yet to emerge. "In the early stages of comics, the writers and artists came from a literary background, rather than a scientific one,' said Wise. 'Superman's origins as an alien may have been influenced by the pulp science fiction of the day, but his qualities were definitely tapped from the archetypes of myth and legend."

The superheroes that quickly followed in the wake of Superman's popularity were created from a similar mold (Figure 4). Batman, who began fighting crime in 1939, was driven by revenge of his murdered parents, relying on his considerable intellect and dark detective methods rather than other-worldly powers. ("He was the mythical god of the underworld to Superman's god of the heavens," observed Wise.) The original Green Lantern drew his power from a magic lantern, much in the way that Aladdin used his magic lamp. The original Flash resembled the Greek god Hermes in both his powers and his cos-

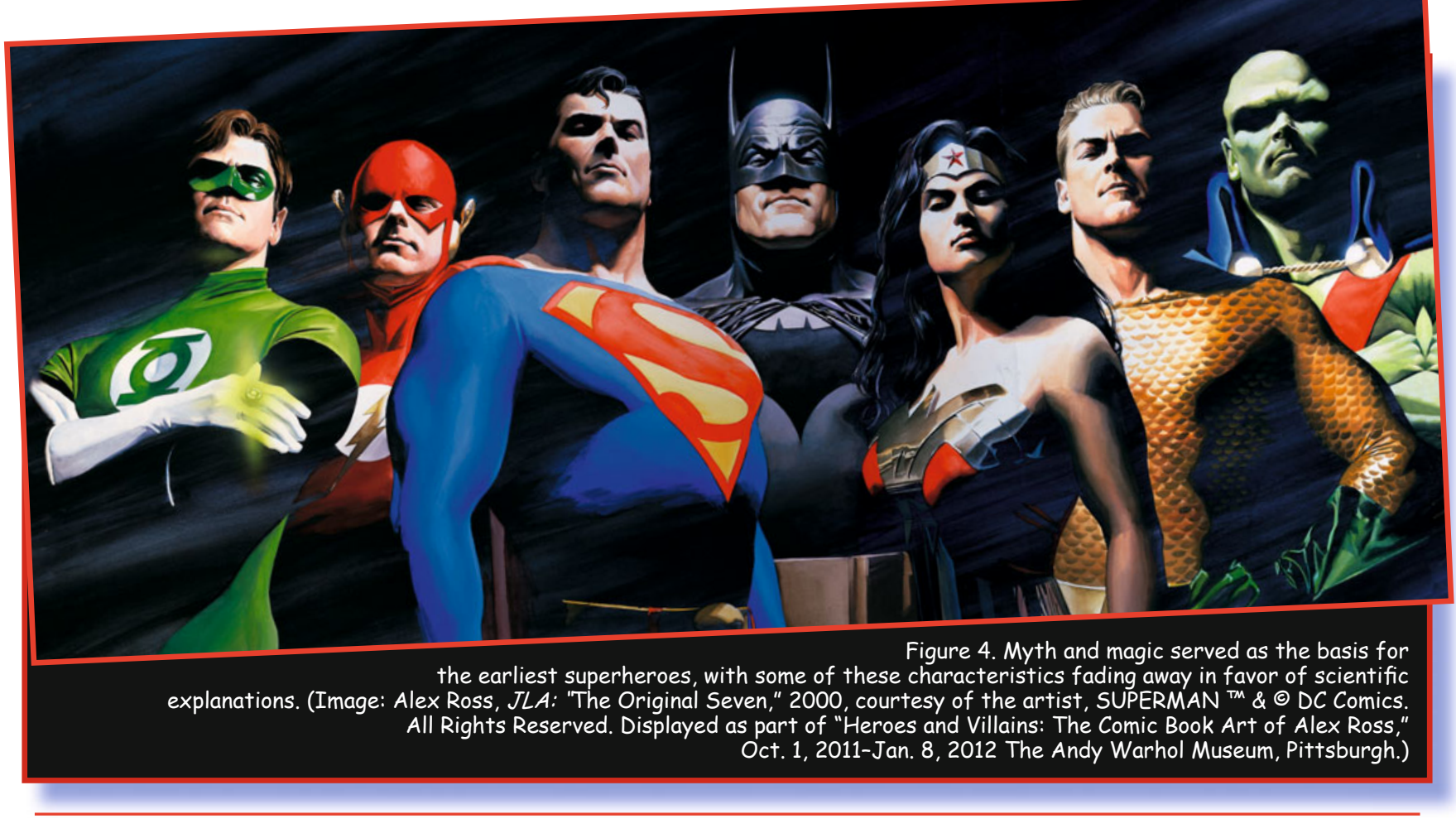




\section{IRONMAN: THE GREATEST MATERIALS SCIENCE AND ENGINEERING SUPERHERO OF ALL}

Ironman is the alter ego of Tony Stark, a brilliant engineer and extremely wealthy industrialist whose stock and trade are the weapons of war (Figure A). Many of the plotlines in the Ironman comics explore the role and issues of technology related to national defense, first within the context of the Cold War when Ironman battled his arch foe, Titanium Man (Figure B), and more recently against terrorism.

Stark was compelled to create Ironman when he was kidnapped for the purposes of creating a super weapon, suffering a mortal chest injury in the process. A fellow prisoner and scientist saved Stark by devising a magnetic chest plate to keep shrapnel from entering his heart. The two then set to work in a primitive workshop to design and construct a futuristic suit of armor, powered to fly, as well as deploy an arsenal of sophisticated weapons. Stark was ultimately able to use the suit to escape, and since then, has constantly upgraded it to match the technological wits of his opponents.
From Ironman's earliest incarnations, his armor contained little actual iron-heavy, dense, and prone to rust, it was not a suitable material for his superhero exploits. Over the years, Stark has dabbled with various titanium alloys, carbon fiber, and nanotechnology for his armor. The design of the armor has evolved as well, from a "chain mail" approach and transistor embedded motors to aid in his movement (Figures $C$ and $D)$, to "bleeding edge" armor stored entirely in his bones (Figure E).
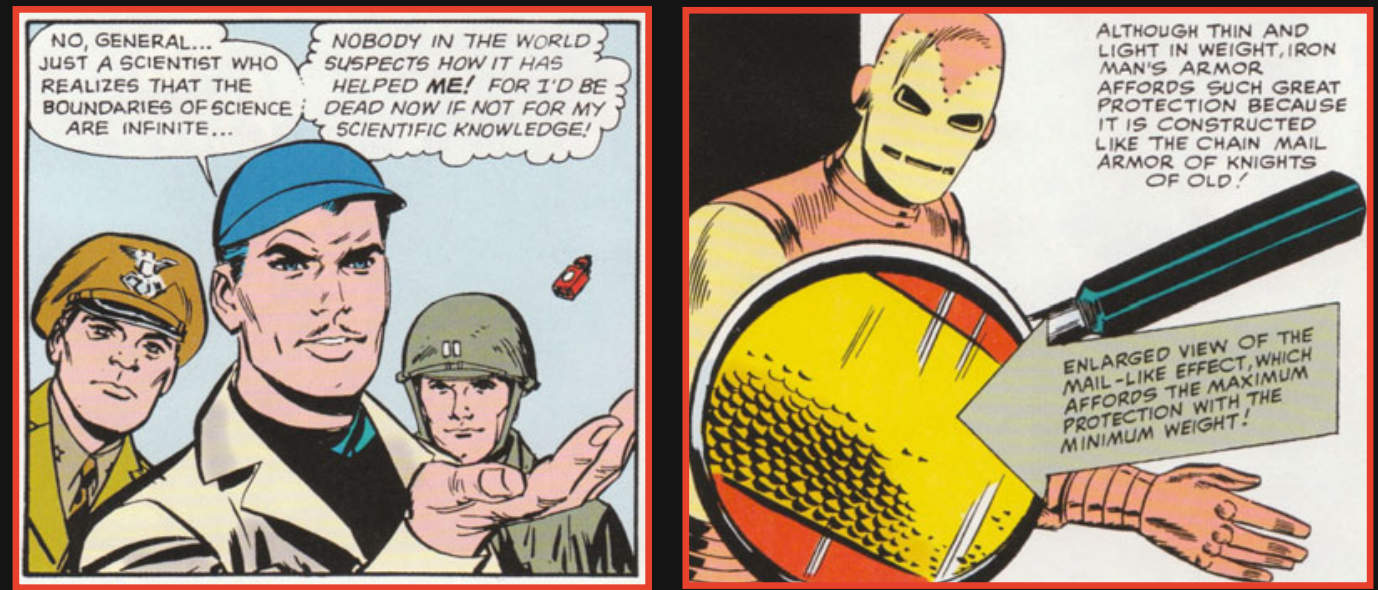

Figure $C$, reprinted with permission: Tales to Astonish V1 N55 May 64 ○ TM Marvel and its subsidiaries. All Rights Reserved.

Figure A. Reprinted with permission: Tales of Suspense V1 N40 Apr. 63 ๑ TM Marvel and its subsidiaries. All Rights Reserved.
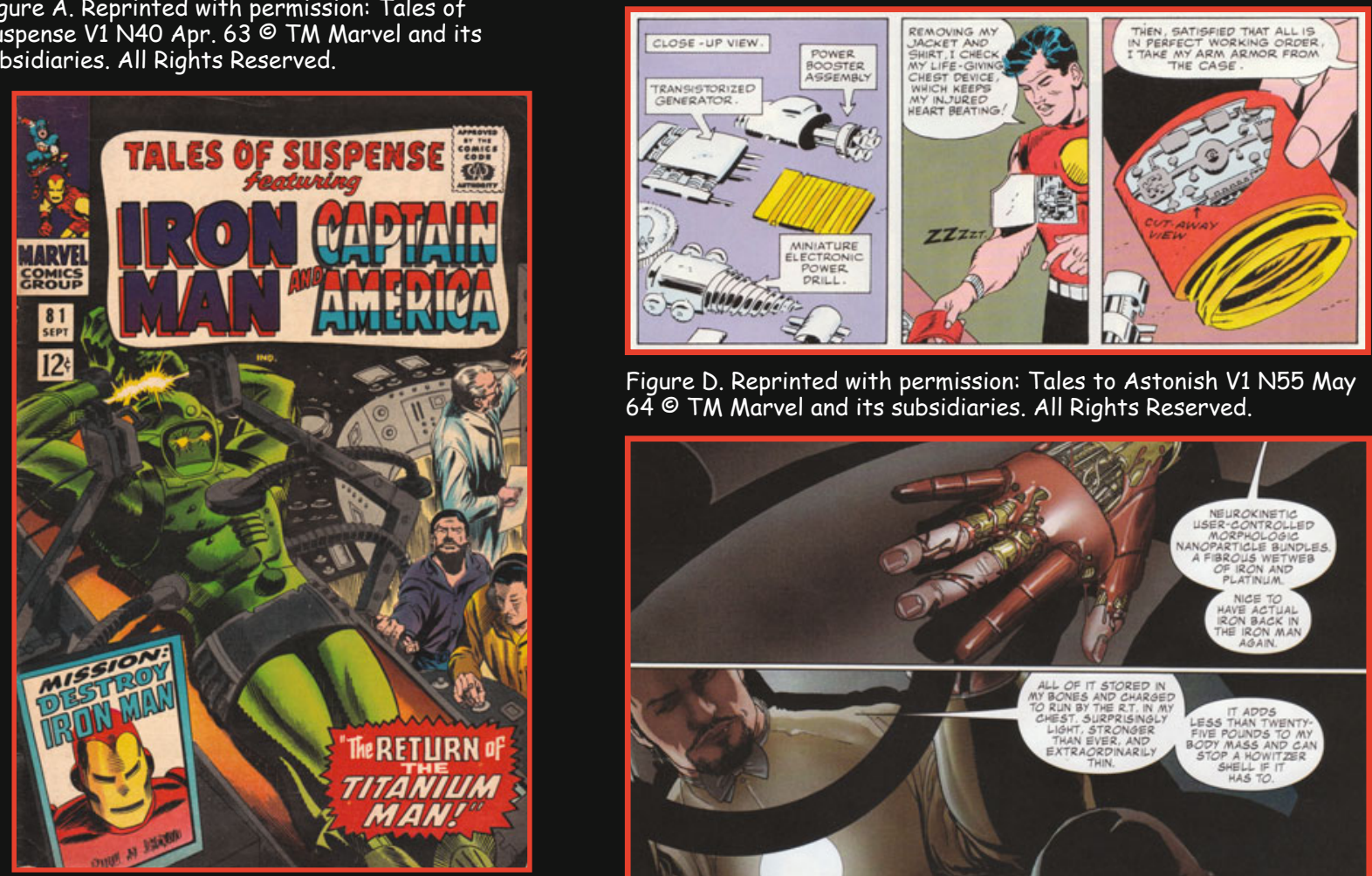

Figure D. Reprinted with permission: Tales to Astonish V1 N55 May $64 \odot$ TM Marvel and its subsidiaries. All Rights Reserved.

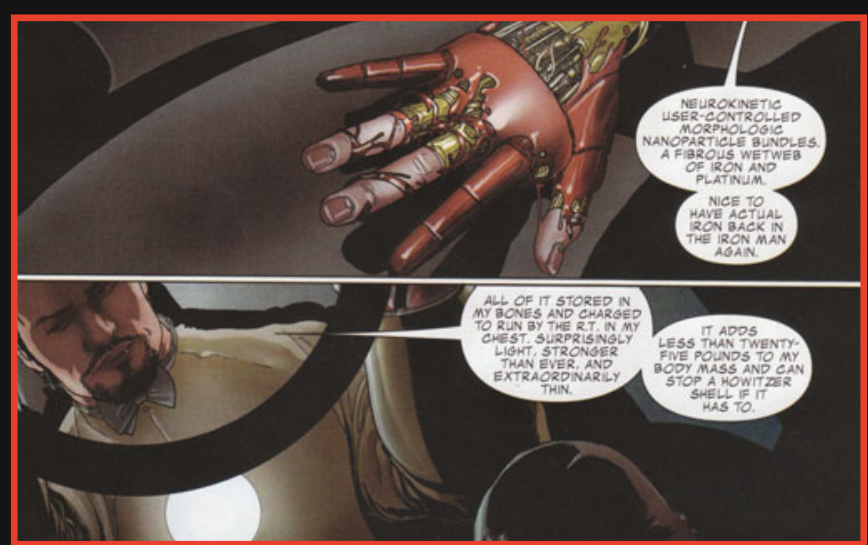

Figure B. Reprinted with permission: Tales of Suspense V1 N81 Sept. 66 ( TM Marvel and its subsidiaries. All Rights Reserved.

Figure E. Reprinted with permission: Invincible Iron Man V5 N30 Nov. $10 \odot$ TM Marvel and its subsidiaries. All Rights Reserved. 


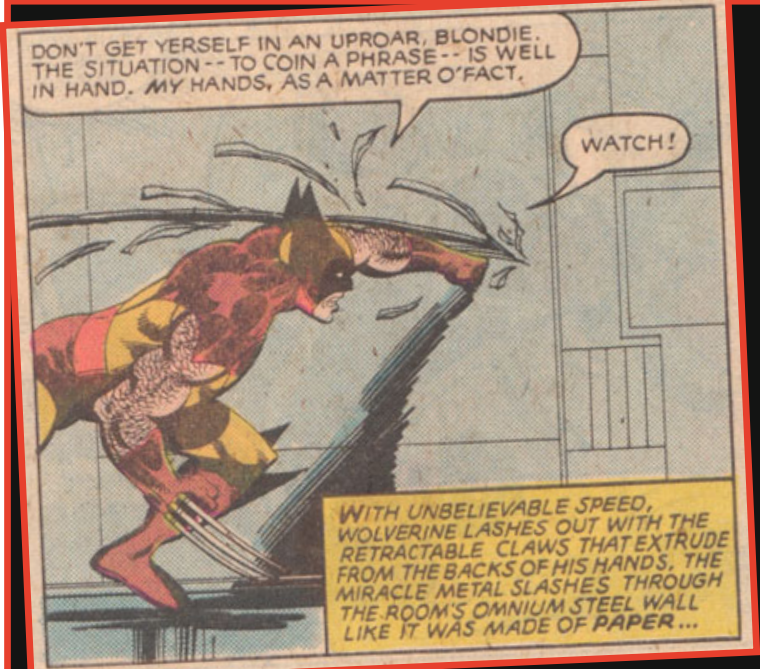

Figure 5. In the Marvel comics universe, the adamantium bonded to the Wolverine character's bones is actually a failed attempt to recreate the vibranium alloy in Captain America's shield. Like many comic materials, it exhibits peculiar properties, most notably setting as a permanent molecular structure eight minutes after being cast. (Image reprinted with permission: The Uncanny $X$-Men V1 N139 Nov. $80 \odot$ TM Marvel and its subsidiaries. All Rights Reserved.)

tume. Sub-Mariner protected the undersea kingdom of Atlantis and Wonder Woman was born of the mythical race of Amazonian women to battle evil with her Lasso of Truth - an interesting characteristic, considering that her creator, William Moulton Marston, also invented the polygraph.

That approach changed with the outbreak of World War II and the rise of a much more technologically proficient threat than the street criminals typically vanquished in the comic pages. Superheroes like Captain America were then created or modified to reflect the importance of technology to the war effort.

The years following World War II were quiet ones for superheroes, noted Wise. A few of the most popular ones remained, conquering crime bosses and landlords once more, while the rest faded away for lack of truly terrifying villains. The Comic Code of 1954 also placed significant restrictions on the words, images, and relationships that could be portrayed, while also feeding the perception that comics were dangerous influences on the nation's impressionable youth.

An emerging anxiety, however, was pricking at the American subconscious, offering a new, albeit faceless, enemy for the superheroes to fight. "The progress of the 1950s was promoted under the shadow of the atomic bomb," said Wise. "Americans embraced technology as a way to make life better, but it could also be the means of wiping us out. The superheroes and their villains that came up through this time were metaphors for that conflict.'
In reflecting the double-edged sword that was scientific progress, new comic characters were developed as flawed individuals wrestling with a multitude of demons, many of them brought on by scientific hubris or folly. Marvel Comics is credited with introducing this contemporary breed of superhero when Reed Richards, the brilliant, but arrogant, leader of the Fantastic Four, launched his stolen rocket ship into space in 1961.

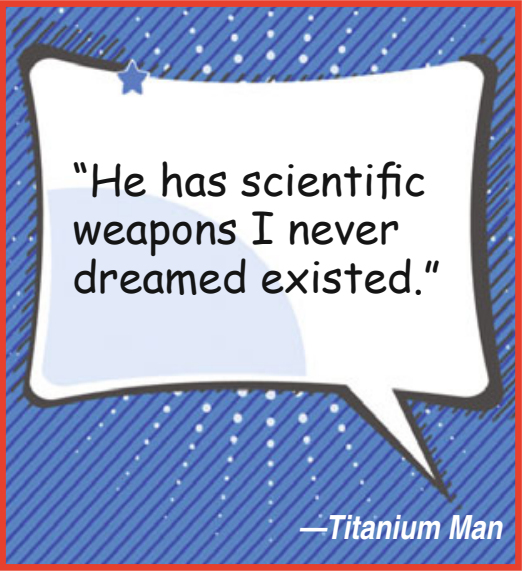

He and his crew were accidently bombarded with "cosmic rays," giving them all super powers, but horribly disfiguring the pilot, Ben Grimm. "Most of the Marvel characters in this new era of comics started out as scientists - and they weren't the stereotypical 'mad geniuses," Wise said. "Reed Richards was the smartest man in the world and used his science for good. But, there was a dark side to his story, as well. He symbolized the overall mood of the country toward science."

Older characters were likewise up-

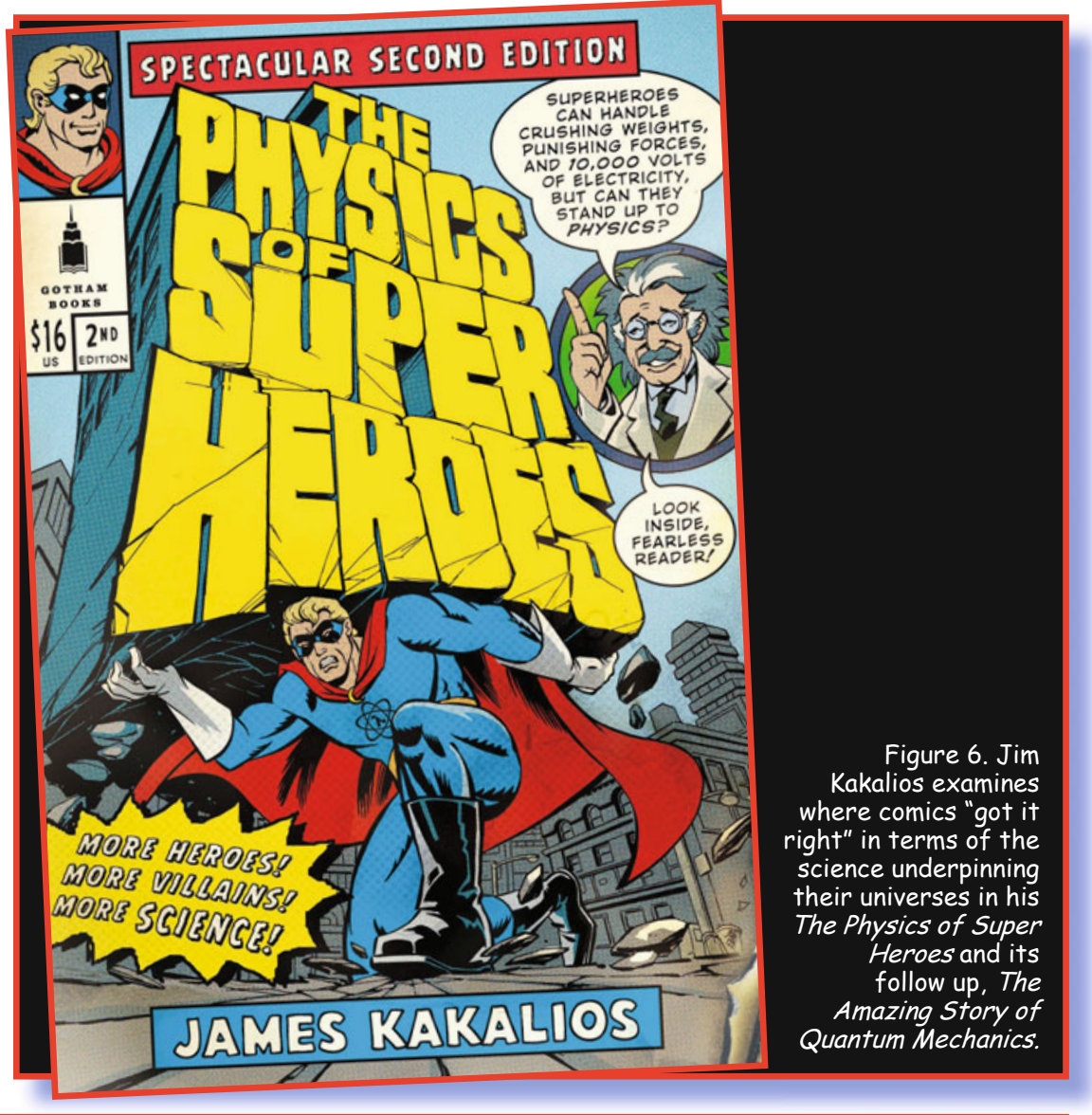




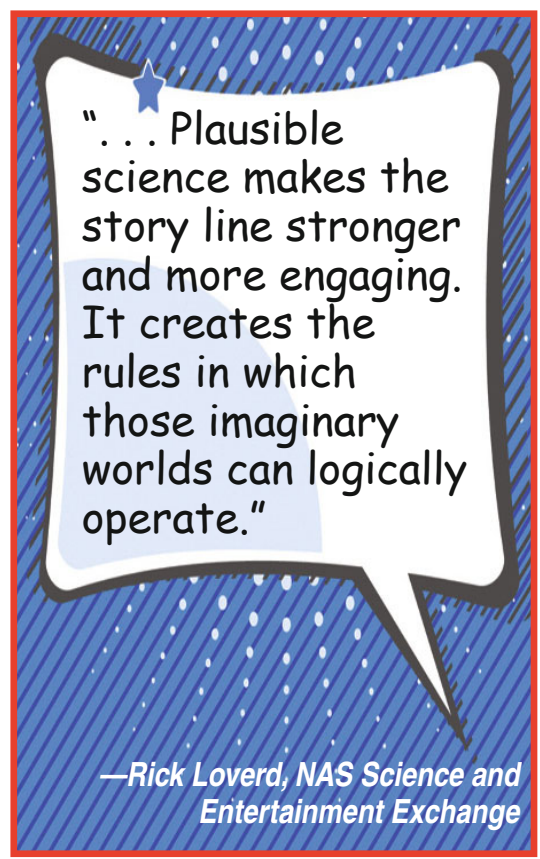

dated to fit the new comic themes, casting off many of their magical qualities. Green Lantern's power was now derived from an alien ring that relied on a master generator. The new Flash fought a rogue's gallery based on scientific principles, such as Dr. Alchemy, who was able to transmute elements. Science in service of national defense also became a target of suspicion-while World War II's Steve Rogers willingly subjected himself to the experiments that ultimately transformed him into Captain America, the Wolverine character in X-Men was kidnapped by a shadowy military operation that forcibly implanted adamantium, yet another ultrastrong fictional alloy, into his skeleton (Figure 5).

"A common theme about this time was the consequences of military researchboth good and bad," said Mathaudhu. "Materials science technologies were particularly dominant in these stories because they underpin nearly everything and were immediately recognizable to the public." (See the sidebar: Ironman: The Greatest Materials Science and Engineering Super Hero of All.)

\section{A LESTURS HALL OP MILLIONS}

The accuracy of the science that shapes these comic adventures has become a special realm of expertise for Jim Kakalios, Taylor Distinguished Professor, School of Physics and Astronomy,
University of Minnesota. Kakalios first started examining the science behind the superheroes as a means of making his freshman physics seminar fun and relevant for non-physics majors. "I grant each character that I use as an example a 'miracle exemption' from the laws of nature," he said. "We assume, for instance, that it is possible to catch bullets in mid-air and then use that to talk about relative velocity. Instead of a final exam, I have the students use analysis and observation to figure out and explain the underlying principles in a given superhero situation - one of my students recently did a presentation on how long the Flash would have to run to use up all of the Earth's oxygen. It's been an effective way to get non-scientific people to look at the world the way a scientist does."

Kakalios has since published two wellreceived books exploring the scientific principles that enable comic characters to perform their fantastic feats (Figure 6). He has also gained some notoriety by using physics to explain a seminal event in comic lore, the death of Spider-Man's first love, Gwen Stacy, who was hurled off a bridge in 1973 by the Green Goblin.

In what is considered the first incidence of a superhero catastrophically failing to save a loved one, Spider-Man catches Gwen by the leg with his web, but when he pulls her up, realizes that she has died. He blames the Green Goblin for her death, and Green Goblin gleefully taunts him in kind. But, Kakalios, applying the laws of physics, proved and published that the sudden stop caused by Spider-Man's webbing snapped her neck, killing her instead of the purported "shock of the fall." Years later, the Spider-Man comic acknowledged Kakalios' explanation in one of its panels, to the physics professor's great delight. "If I can teach a homicidal maniac like Green Goblin the conservation of momentum, I can teach anything," he laughed.

Generally, said Kakalios, comics have succeeded in "getting the science right," within the structure of the universes that they have created. Concepts and theories such as black holes, mobile devices, and even the internet have been presented with a fair measure of accuracy years before they became common knowledge. Wayne Wise noted that this shouldn't be surprising. "Many comic writers look to science for inspiration," he said. "These ideas feel larger than life when you are first exposed to them, which suit these larger-than-life stories and characters."

Given his interest and expertise, Kakalios has made his own contributions to the scientific integrity of the superheroes as a consultant on comic-based movies,

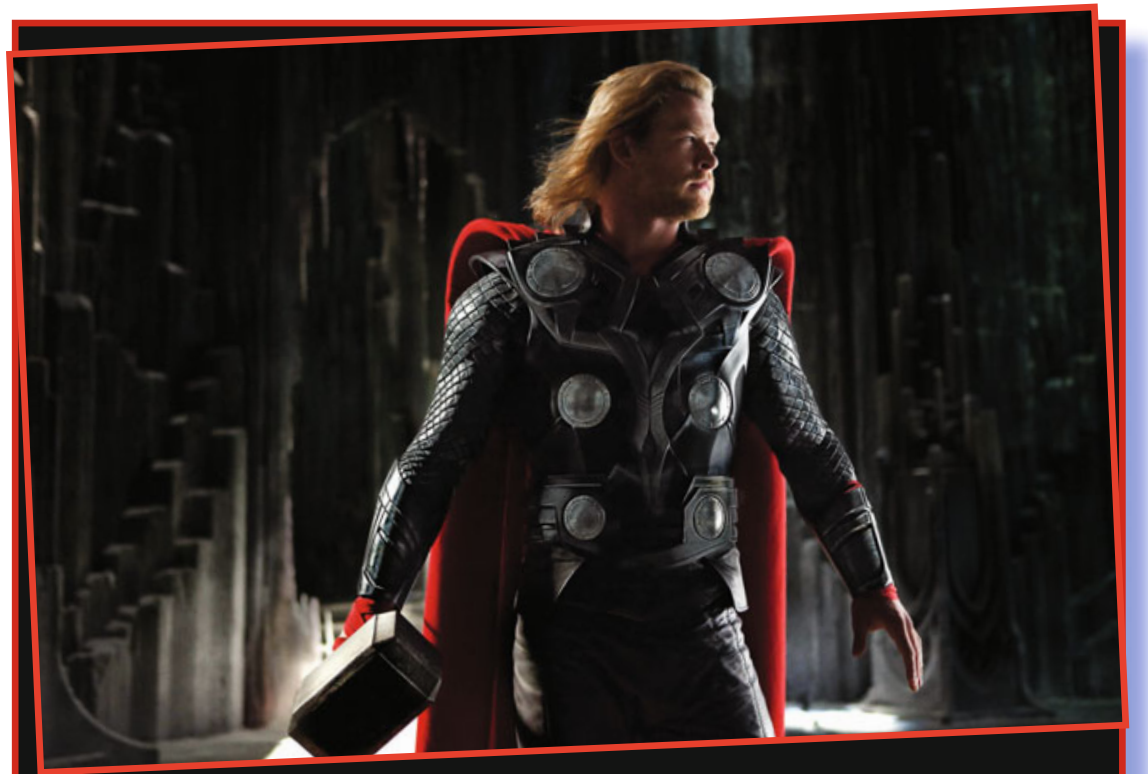

Figure 7. The National Academy of Sciences Science and Entertainment Exchange connected scientific experts with the creators of the 2011 movie version of the Thor comic to provide a scientific context to the fantastic tale of a Norse god fallen to Earth who wields a mighty hammer forged in the heart of a dying star. (ङ2011 Marvel. All character names and their distinctive likeness: TM \& O2011 Marvel Entertainment Inc. and its subsidiaries. All Rights Reserved.) 
including The Amazing Spider-Man, due out in the summer of 2012. His first experience in this type of endeavor was to consult on the movie version of the graphic novel, The Watchmen, specifically to ensure a scientific grounding behind how a main character, Dr. Manhattan, could appear in multiple locations at the same time. It was then that he also realized the tremendous potential of comics and their movie incarnations as a teaching tool. With the studio's permission, he created and posted a lecture on You Tube that discussed the science of The Watchmen prior to the opening of the film, illustrated with yet-to-be released footage. Anticipation of the movie was so great that the video received 1.7 million views (view the video at http://www.youtube. com/watch? $v=z m j 1 r p z D R Z 0)$. "I could give the same talk on quantum mechanics in a lecture hall for several centuries, and still not reach that many people," he said. "The interest in comics and their films is a powerful platform to talk about science to a broader audience."

"There are a real desire and a real need for science outreach," he continued. "Part of the problem that we, as scientists, have had historically in communicating with the general public is that we explain things in such a stilted manner and with so many provisions - We come off as pedantic and inaccessible. I believe that, generally, the public is on our side. People are not anti-intellectual, but they are anti-snobbery. Comics and other popular culture give us the opportunity to talk about science in an open and accessible way-Chances are that people will relate to and remember concepts presented through these stories. That's important because, as citizens and voters, we are being called upon more and more to make informed opinions about technology issues. This is an effective way of arming people with a basic understanding of scientific principles and issues so that they can make those decisions."

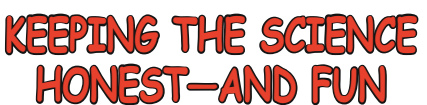

According to Marty Perreault and Rick Loverd of the National Academy of Sciences' (NAS) Science and Entertainment Exchange, many of the creators of fictional universes take this responsibility for accurately portraying science

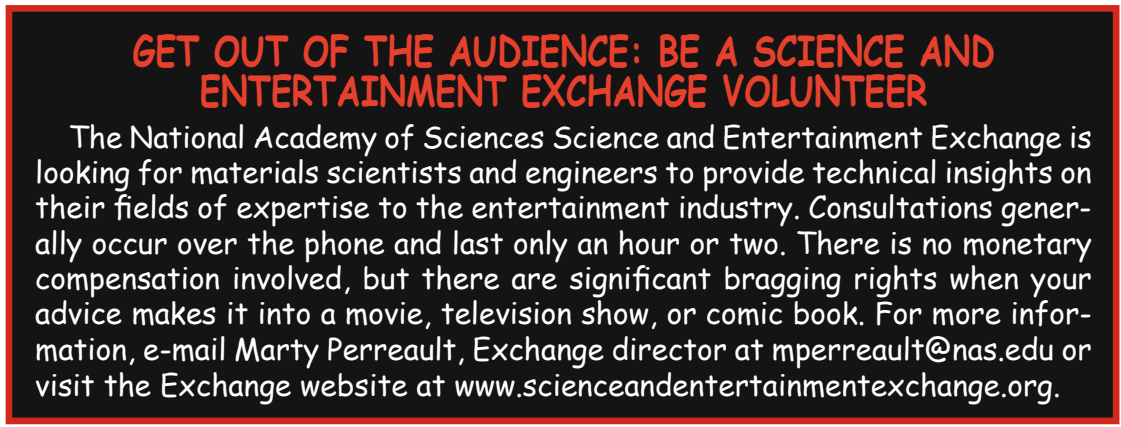

in their works very seriously. The Exchange was established in 2008 by NAS to provide a resource for accurate scientific information to the entertainment industry. "It's an offshoot of what the NAS does generally, which is to provide accurate information to the public," said Perreault, Exchange director. Equipped with a small army of scientist volunteers, the Exchange fields requests from writers, producers, and directors for insights on how science can accurately and appropriately inform their creations. The consults are generally free, ranging from a quick fact check to an extended briefing. The Exchange also regularly arranges invited information sessions where creative people can learn about the latest scientific breakthroughs from the experts who are researching them. (See the sidebar: Get Out of the Audience: Be a Science and Entertainment Exchange Volunteer.)

"What we have found is that the science is much further ahead of what entertainers usually envision. The creative people who attend these sessions come away inspired and excited to use these cutting edge ideas in their work," said Loverd, Exchange director of development. "Many in the entertainment industry feel an imperative to 'get the science right," he said. "They know that almost everyone in the audience now has a supercomputer in their pockets. Audiences are more savvy to science than they were in the past, and more questioning of some of the ideas. If what they see on the screen doesn't mesh with information that they have access to online, it takes them out of the story - If they are thinking about why the science doesn't make sense, then they are not thinking about the characters.

"That's not to say that everything in a movie needs to be deadly accurate," Loverd said. "The story will always trump the science, but plausible science makes the story line stronger and more engaging. It creates the rules in which those imaginary worlds can logically operate."

The Exchange has arranged more than 350 scientific consults since its inception. While it counts blockbuster films such as Thor (Figure 7) and the upcoming Avengers among its projects, much of the organization's work focuses on helping shape ideas, concepts, and universes that may be years in the making. "We know that $99 \%$ of scripts may never make it to the screen," said Perreault. "But we need to be available to the 99 so that we can ensure that the 1 that ultimately does get produced is scientifically accurate. By helping portray science in a great manner, our intent is to inspire a curiosity about it that will help produce the next generation of scientists and engineers."

Mathaudhu agrees, both from his personal experience as a comic fan and in his attempts to inspire new thinking through comic mythology, that the colorful tales of good and evil are powerful tools for shaping perception of what can be scientifically possible. "Even the superheroes born with powers have the technical acumen to augment them," he said. "The focus in most superhero comic stories is a problem or puzzle that requires science to resolve. The hero is always the person who can figure it out and create the technology that saves the day."

"And, doesn't everyone want to be a superhero, when you come down to it?"

\section{AGKNOWLEDEEMENTS}

JOM extends a special thanks to Suveen Mathaudhu for sharing his knowledge, enthusiasm, and support in developing this article, as well as researching and obtaining the many Marvel images that illustrate the piece.

Lynne Robinson is a news and feature writer for TMS. 